\title{
Dissociation and coagulation of caseins and whey proteins in concentrated skim milk heated by direct steam injection
}

\author{
Joseph Dumpler $^{1}$ (D) Heidi Wohlschläger ${ }^{1}$. \\ Ulrich Kulozik $^{1}$
}

Received: 31 May 2016 / Revised: 14 July 2016 / Accepted: 12 September 2016 / Published online: 10 October 2016

C) INRA and Springer-Verlag France 2016

\begin{abstract}
Heat treatment of concentrated milk systems for preservation and long shelf life or at least a sufficient removal of food pathogens prior to spray drying is a crucial step due to the decreasing stability of these systems toward heat compared to unconcentrated milk. Heat-induced coagulation is observed when temperature-time combinations for the achievement of certain microbial inactivation effects are higher than the heat and colloidal stability of the concentrated milk system allows. In this work, the effects of direct steam injection on the stability of casein micelles in concentrated skim milk (CSM) of 18, 23, and 27\% total non-fat solids, heat-treated by direct steam injection (DSI), were investigated. Quantitative differential centrifugation for the separation of aggregates, casein micelles, dissociated submicellar particles, and soluble proteins and subsequent analysis of caseins and whey proteins within these fractions by RP-HPLC were applied. Quantitative separation was monitored by particle size measurements. The dissociation of $\mathrm{k}$-casein as well as an increase in casein micelle hydrodynamic radius were observed to increase with increasing total solid content of $\mathrm{CSM}$, heat treatment time, and temperature. Heat-induced dissociation of $\beta$-Lg-Kcasein complexes at a critical level of $30-35 \%$ was found to induce severe coagulation of $\mathrm{K}$-casein-depleted calcium-sensitive casein micelles in CSM heated by DSI. Dissociated and aggregated proteins were found to be present as distinct colloidal particle classes differing in size from casein micelles.
\end{abstract}

Keywords Heat stability C Concentrated milk - Casein micelle stability - Direct steam injection

Joseph Dumpler

joseph.dumpler@tum.de

1 Chair for Food and Bioprocess Engineering, Technical University of Munich, Weihenstephaner

Berg 1, Freising-Weihenstephan, Germany 


\section{Introduction}

Concentrated skim milk (CSM) prepared by evaporation or reverse osmosis is manufactured as an intermediate product for spray-dried powders or long-life dairy products such as evaporated milk in today's dairy industry. Prior to spray drying, total solid concentrations of 40-50\% are desirable due to the high energy consumption of the drying process per kilogram of water removed compared to evaporation. Interestingly, the structure and integrity of casein micelles remain unaltered in concentrated milk systems and the effects on micelle hydration, charge, and colloidal calcium phosphate are reversible upon dilution depending on temperature and time of storage. Viscosity changes were attributed to an increase in the volume fraction of casein micelles which can be considered as highly hydrated spherical microgel particles (Olivares et al. 2016). High heat treatment of highly concentrated milks is relatively unusual to date due to immediate spray drying for preservation, low heat stability, and high fouling potential. Nevertheless, concentrated milk with $18-22 \%$ total non-fat solids is usually sterilized either in containers or these days more frequently continuously by heat exchangers. Problems associated with evaporated milk manufacture are usually reported as coagulation of evaporated milk during heat treatment, sediment formation, and age gelation during storage (Muir 1984; Hinrichs 2000; Smith and Malmgren 1999). Heat stability, i.e., the ability of concentrated milk systems to withstand a certain heat load, has been investigated for many decades in the context of sterilized evaporated milk. Mostly, these instabilities of concentrated milk toward heat treatment are referred to the casein micelles and their decreasing stability in a low $\mathrm{pH}$, high ionic strength, and especially high soluble calcium environment (Crowley et al. 2014; Crowley et al. 2015; On-Nom et al. 2012; Sievanen et al. 2008).

Heat-induced coagulation of overall protein was taken as a means for characterization of changes in concentrated milk either by visual determination or by automated methods. The effects of serum composition, technological treatments, and total solids on the onset of coagulation of milk and concentrated milk have been extensively characterized on a lab scale in batch heating systems of small amounts of sample (Fox 1981; Fox and Hearn 1978; Huppertz and Fox 2006; Huppertz 2014; Morrissey 1969; Rose 1961, 1962; White and Davies 1958; Muir et al. 1979; White and Davies 1966; Kelly and Roefs 1990). Dissociation of $\mathrm{K}$-casein together with associated $\beta$ lactoglobulin as well as chemical reactions are considered as the main destabilizing effects on casein micelles leading to aggregation (Singh and Fox 1986, 1985, 1987a, 1987b; Singh and Latham 1993; van Boekel et al. 1989). However, further physical reactions preceding coagulation, their extent required to induce coagulation, and the kinetics of these elementary steps, especially in continuous heating systems like direct steam injection heat treatment, have been studied to a much lesser extent. Some studies have reported on heat-induced dissociation of $\mathrm{K}$-casein from casein micelles in milk and concentrated milk on a laboratory scale (Anema 1998; Anema and Klostermeyer 1997; Anema and Li 2003). However, a clear correlation between heat-induced coagulation and the dissociation of caseins and whey proteins from micelles was not investigated to our knowledge.

In a previous publication, we found that there is a strong relationship between the total solid content as well as temperature and duration of a heat treatment on the onset of protein aggregation in CSM which had first been established on a lab 
scale (Dumpler and Kulozik 2015). Using direct steam injection, we could show that chemical reactions can be considered as unnecessary for heat-induced coagulation of CSM (Dumpler and Kulozik 2016). Particle size measurement revealed that for the induction of coagulation, native casein micelles first increase in size and during coagulation, disintegration of more and more micelles leads to small particles $<100 \mathrm{~nm}$ and the formation of large proteinaceous particles in the range of 3-100 $\mu \mathrm{m}$. However, the composition of the large particles and small submicellar particles, the reason for the rapid increase in sedimentable protein, and the involvement of whey proteins in the coagulation process of CSM heated by direct steam injection (DSI) were still uncertain.

Therefore, in this study, we further addressed possibilities to quantitatively separate and analyze all the different protein fractions by differential centrifugation and subsequent analysis by an RP-HPLC method according to Bobe et al. (1998).

The determination of the distribution of caseins and whey proteins in the coagulated and dissociated fraction was intended to give mechanistic insights into the determinants of the onset and progression of the coagulation process of CSM.

\section{Materials and methods}

\subsection{Concentrate manufacture and heat treatments}

Pasteurized skim milk was obtained from a local dairy (Molkerei Weihenstephan, Freising, Germany). The average main composition of the skim milk and preparation of concentrates by reverse osmosis were as described by Dumpler and Kulozik (2015). Heat treatments of CSM of 18, 23, and 27\% total solids at different temperatures and holding times using pilot-scale DSI were performed as described previously.

\subsection{Centrifugal separation of protein fractions in heat-treated concentrated skim milk}

The procedure for the separation of the different particle fractions is summarized in Fig. 1. Centrifugation of heat-treated concentrated skim milk at $4.000 \times g$ for 10 min using a laboratory centrifuge (Multifuge 1S-R, Heraeus Holding GmbH, Hanau, Germany) was used to separate colloidal soluble casein particles from aggregated casein particles (fraction 1). The supernatant was then used for RPHPLC analysis. The composition of the small particles (fraction 3) was determined by ultracentrifugation of the heat-treated concentrated skim milk for removal of colloidal stable casein micelles (fraction 2) from the supernatant. Five hundred microliters of centrifugal supernatant was added to $900 \mu \mathrm{L}$ of distilled water in a 1.5-mL Ultra Microtube (Thermo Scientific, NC, USA), properly mixed and centrifuged at $48.800 \times g$ for $26 \mathrm{~min}$ at $25^{\circ} \mathrm{C}$ using a Thermo Scientific Sorvall WX80+ ultracentrifuge equipped with a Fiberlite F50L-24x1.5 rotor (Thermo Electron LED GmbH, Langenselbold, Germany). Therefrom, $900 \mu \mathrm{L}$ of supernatant containing soluble protein and small casein micelle particles was withdrawn and used for further analysis. 


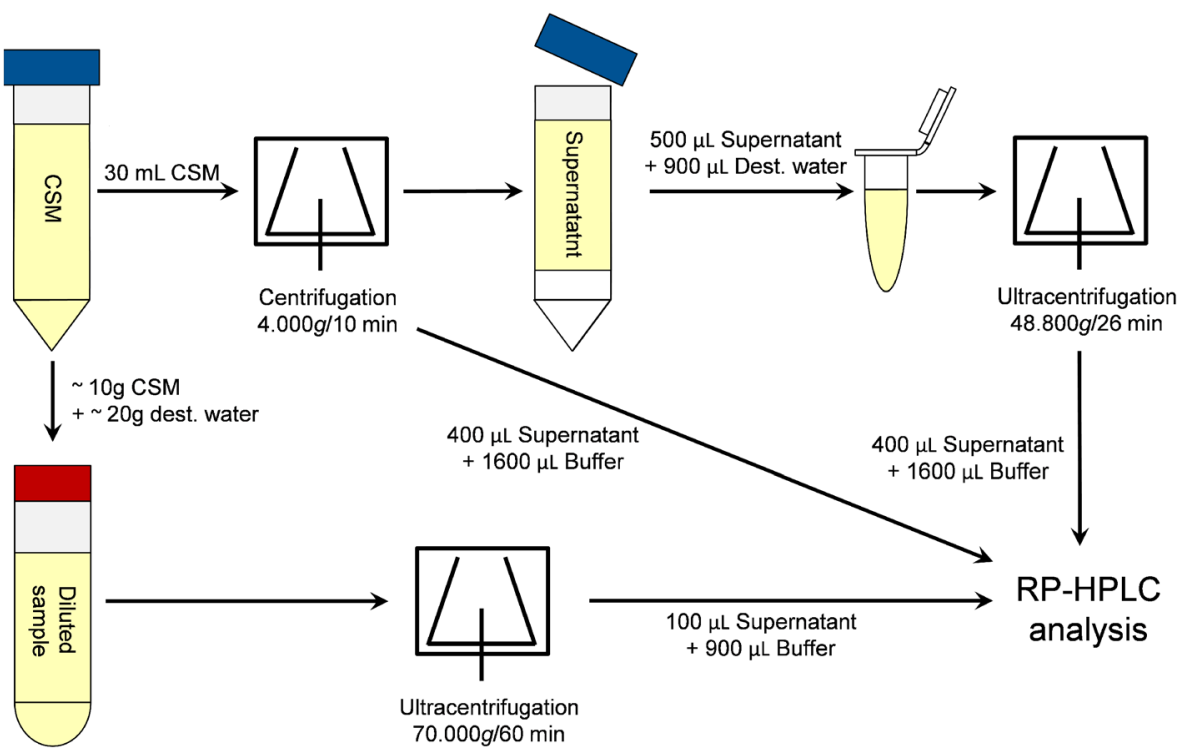

Fig. 1 Sample preparation procedure for separation of the different particle fractions and RP-HPLC analysis

For complete removal of colloidal protein and the determination of soluble protein (fraction 4), heat-treated CSM was diluted at approximately 1:3 $(w / w)$ and approximately $30 \mathrm{~g}$ were filled into the centrifuge tubes. Ultracentrifugation was performed at $70,000 \times g$ for 60 min at $25^{\circ} \mathrm{C}$ using a Beckman Coulter L7-65 equipped with a Ti-70 rotor (Beckman Coulter $\mathrm{GmbH}$, Krefeld, Germany). One hundred microliters was pipetted from the centrifuge tubes by carefully immersing the pipette tip through the thin lipid phase on top into the serum phase.

To summarize, this procedure aimed at separating four different classes of particles depending on their particle size and sedimentability.

Fraction 1: Aggregated protein $(3-100 \mu \mathrm{m})$ sedimented at 4,000 $\times \mathrm{g} / 10 \mathrm{~min}$

Fraction 2: Colloidal stable micelles (100-1000 nm) sedimented at 48,800 $\times \mathrm{g} / 26 \mathrm{~min}$

Fraction 3: Submicellar particles $(20-100 \mathrm{~nm})$ sedimented at $70,000 \times \mathrm{g} / 60 \mathrm{~min}$

Fraction 4: Soluble protein $(<20 \mathrm{~nm})$, non-sedimentable

\subsection{RP-HPLC analysis of major soluble proteins in concentrated skim milk}

Supernatants containing individual fractions were dissolved in guanidine buffer for denaturation and dissolution according to Bobe et al. (1998) with some modifications for simplification of the sample preparation procedure, shorter run times, and reproducibility. This method needed some improvements according to concerns raised by the authors. Therefore, the major objectives concerning this method development were

- Modification and optimization of this method for the analysis of CSM

- Sample stability at room temperature

- Simplicity of sample preparation

- No carryover between individual runs 
- Proper resolution as well as quantification of caseins and whey proteins in one single run

Attribution of different genotypes of caseins to the resulting spectrum of peaks was done according to Bonfatti et al. (2008). Compared to Bobe et al. (1998), we used five times the amount of sodium citrate $(21.5 \mathrm{mM})$ to ascertain that colloidal calcium phosphate gets completely dissolved even in concentrated milk and to have an additional buffering capacity. Thereby, the final $\mathrm{pH}$ of the buffer solution was 7.2. In contrast to Bonfatti et al. (2008) reporting instability of the milk proteins, especially the whey proteins when dissolved in guanidine buffer and left at room temperature for several hours, we diluted milk, supernatant, or concentrated milk in the buffer in a ratio of 1:5. This results in a higher final guanidine concentration $(5.1 \mathrm{M})$ in the prepared samples. Doing so, we could not observe a decrease in the amount of whey proteins even after storage of the sample plus buffer solutions for $72 \mathrm{~h}$ at room temperature (data not shown). This decay in the detectable amount of whey proteins in the samples of Bonfatti et al. (2008) is likely to have occurred due to the incomplete denaturation of whey proteins or subsequent refolding at lower guanidine concentrations as investigated by Greene and Pace (1974). This buffer solution was also proven to be superior to a urea buffer solution as described by Bonizzi et al. (2009) for our purpose as it allows separating and quantifying caseins and whey proteins in one single run and gives a better resolution of individual caseins. Analytical standards of individual caseins and whey proteins were purchased from Sigma-Aldrich, Steinheim, Germany.

As a sample preparation procedure, $400 \mu \mathrm{L}$ of concentrated milk or supernatant was dissolved in $1600 \mu \mathrm{L}$ of guanidine buffer as a single-step sample preparation and left for at least $30 \mathrm{~min}$ at room temperature for complete dissolution. The mixture was then filtered through a $0.45-\mu \mathrm{m}$ regenerated cellulose syringe filter into a screw-capped glass vial. In the case of ultracentrifugal supernatant treated at $70,000 \times \mathrm{g}$ for $60 \mathrm{~min}$, $100 \mu \mathrm{L}$ was dissolved in $900 \mu \mathrm{L}$ buffer solution and treated similarly.

Analysis was performed on an Agilent 1100 Series chromatograph (Agilent Technologies, Waldbronn, Germany) equipped with a binary pump. The system was controlled by Agilent ChemStation software (Rev. B.04.03). Separation was performed on a C18 analytical silica-based column (Agilent Zorbax 300SB-C18, $4.6 \times 150 \mathrm{~mm}$, $5 \mu \mathrm{m}$ ). An analytical guard cartridge (Agilent Zorbax 300SB-C18, $4.6 \times 12.5 \mathrm{~mm}$ ) was used.

Solvent A consisted of $0.1 \%$ trifluoroacetic acid (TFA) in 90\% HPLC grade water and $10 \%$ acetonitrile. Solvent B was $0.07 \%$ TFA in $10 \%$ HPLC grade water and $90 \%$ acetonitrile. The flow rate was $1.2 \mathrm{~mL} \cdot \mathrm{min}^{-1}$, the column temperature was $\mathrm{kept}$ constant at $40{ }^{\circ} \mathrm{C}$, and detection was made at a wavelength of $226 \mathrm{~nm}$. Injection volume was chosen between 20 and $80 \mu \mathrm{L}$ depending on the expected concentration of proteins within the sample. The following gradient was used for separation: linear from 27 to $32 \%$ in $2 \mathrm{~min}, 32$ to $38 \% \mathrm{~B}$ in $8 \mathrm{~min}, 38 \% \mathrm{~B}$ for $3 \mathrm{~min}$, from 38 to $40 \% \mathrm{~B}$ in $3 \mathrm{~min}$, from $40 \% \mathrm{~B}$ to $42 \%$ in $4 \mathrm{~min}$, from 42 to $44 \% \mathrm{~B}$ in $2 \mathrm{~min}$, and $44 \% \mathrm{~B}$ for $0.5 \mathrm{~min}$, then rinsing with $100 \% \mathrm{~A}$ for $4.5 \mathrm{~min}$ and $100 \% \mathrm{~B}$ for $4 \mathrm{~min}$ and returning to $27 \% \mathrm{~B}$ within $0.5 \mathrm{~min}$. The total time of each run was therefore $31 \mathrm{~min}$. Coefficients of variation for a five times sample preparation (repeatability) were 0.52, 2.25, 2.16, 1.96, $2.01,1.03$, and $1.04 \%$ for $\kappa$-casein, $\alpha_{\mathrm{S} 2}$-casein, $\alpha_{\mathrm{S} 1}$-casein, $\beta$-casein, $\alpha$-lactalbumin, $\beta$ lactoglobulin $\mathrm{B}$, and $\beta$-lactoglobulin $\mathrm{A}$, respectively. Coefficients of variation were 
slightly higher for heat-treated milk samples. Four subsequent $80-\mu \mathrm{L}$ injections of $6 \mathrm{~N}$ guanidine buffer ("blank injection") at a run time of 2 min each at $100 \%$ solvent A were used as a cleaning procedure. A subsequent shortened blank run of 7 min with $80 \mu \mathrm{L}$ of blank injection was used for cleaning the pre-column and column if carryover of $\alpha_{\mathrm{S}^{-}}$ casein and $\beta$-casein was detected.

The relative amount of caseins and whey proteins was calculated from the relative peak areas of heat-treated and centrifugally separated CSM, i.e. the supernatant fraction, compared to the unheated centrifuged samples. Heat treatment of milk and concentrated milk leads to the formation of pre-peaks relative to the main whey protein peak of $\alpha$-lactalbumin, $\beta$-lactoglobulin B, and $\beta$-lactoglobulin A. Standard deviations were calculated from two individual samples of each heat treatment that was performed in duplicate $(n=4)$. Data was plotted and statistical analysis was performed using OriginPro 2015G (OriginLab Corporation, Northampton, MA, USA). A paired sample $t$ test was used to test for significance between treatments and the amounts of individual proteins in the supernatant fractions.

\subsection{Particle size analysis}

Particle size measurements of CSM heat-treated by direct steam injection and uncentrifuged and centrifuged at 4,000 $\times \mathrm{g}$ for $10 \mathrm{~min}$ were performed on a Malvern Mastersizer 2000 equipped with a Malvern Hydro 2000S sample dispersion unit (Malvern Instruments GmbH, Herrenberg, Germany) as described in an earlier publication (Dumpler and Kulozik 2016). Each sample was measured in duplicate at $20{ }^{\circ} \mathrm{C}$. Results are reported as the mean of two trials including measurements of two individual samples.

Supernatants of the centrifugation at $4,000 \times g$ for $10 \mathrm{~min}$ were diluted 1:50 in simulated milk ultrafiltrate (SMUF) according to Jenness and Koops (1962) and measured by photon correlation spectroscopy (PCS) in a Malvern Zetasizer Nano ZS (Malvern Instruments GmbH, Herrenberg, Germany) as described previously. Supernatants of the centrifugation at $48,800 \times g$ for $26 \mathrm{~min}$ were diluted 1:5 with SMUF. Results of the particle size measurements reported in this study were calculated as means of eight measurements of two individual samples and two individual trials. Data were transformed into a logarithmic density distribution $\mathrm{q}_{3}[\ln (\mathrm{x})]$ for better interpretability of the bimodal distributions observed.

\section{Results and discussion}

\subsection{Particle size distributions in heat-treated and fractionated concentrated skim milk}

The measurement of particle size and particle size classes in CSM was performed due to two different assumptions made based on visual observations. First, we observed a rather white appearance and a higher viscosity of CSM after heat treatment which indicated that whey proteins have denatured upon heating and casein micelles had increased in size during heat treatment. Second, we could see a relatively rapid formation of sediment in samples that had coagulated even without acceleration of 
the sedimentation process by centrifugation. This indicated that large protein microparticles were formed due to the heat treatment. The sample preparation procedure based on these observations aimed to quantitatively fractionate the different particle classes. This was checked by the resulting particle size data. RP-HPLC was then used to determine their protein composition either directly or indirectly by analysis of the protein composition of the supernatant fractions.

Figure $2 \mathrm{a}, \mathrm{b}$ shows the particle size distribution of CSM after heat treatment determined by laser light diffraction based on Mie theory (Mastersizer 2000) of the whole CSM ample as well as the supernatant of CSM centrifuged at $4,000 \times g$ for 10 min. Figure $2 \mathrm{c}, \mathrm{d}$ shows the results of the PCS measurements of the supernatants of $4,000 \times g$ for $10 \mathrm{~min}$ and the ultracentrifugal supernatant of $48,800 \times g$ for $26 \mathrm{~min}$. The two different instruments were used as the whole range of particle sizes over four decades of size within the heat-treated CSM samples could only be covered by using two instruments. The supernatant fraction of $4,000 \times \mathrm{g} / 10 \mathrm{~min}$ was found not only to contain non-aggregated casein micelles, but with increasing temperature, there was a marked increase in particles in the range of 20-100 nm. These particles could not be detected by laser light diffraction measurements based on Mie theory as the instrument had a detection limit of $40 \mathrm{~nm}$.
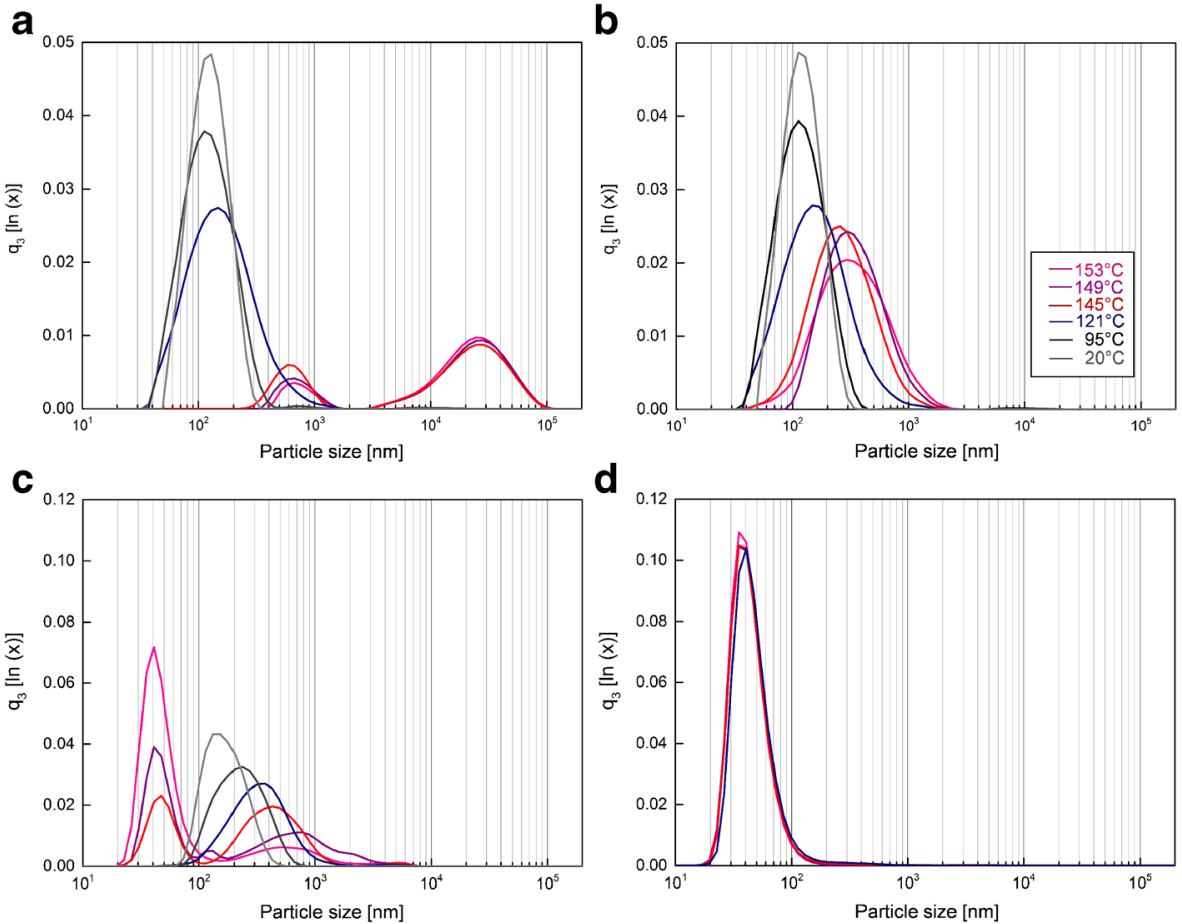

Fig. 2 Logarithmic density distributions of CSM heat-treated at different temperatures at $23 \%$ total solids for a constant holding time of $10 \mathrm{~s}$ and subjected to differential centrifugation. Panels $\mathbf{a}, \mathbf{b}$ were obtained by using laser light diffraction based on Mie theory and panels $\mathbf{c}, \mathbf{d}$ were obtained by PCS. a Density distribution of the whole sample, $\mathbf{b}$ of the supernatant fraction $(4,000 \times \mathrm{g} / 10 \mathrm{~min}), \mathbf{c}$ of the supernatant fraction $(4,000 \times \mathrm{g} / 10 \mathrm{~min})$, and of the supernatant fraction $(48,800 \times \mathrm{g} / 26 \mathrm{~min})$ 
It can be seen from the graphs (Fig. 2a, b) that centrifugation conditions at $4,000 \times g$ for $10 \mathrm{~min}$ resulted in a complete removal of large aggregates so that we could assume that the determination of proteins in the supernatant by RP-HPLC would give us quantitative information about the relative amount of individual aggregated caseins. In addition to this, we could observe a marked increase of the hydrodynamic radius of the casein micelles. This increase in hydrodynamic radius was dependent on both total solid content and holding time during heat treatment which will be discussed in more detail further down. O'Connell and Fox (2000) have shown that the velocity of increase is higher for larger micelles compared to smaller ones. This can be used to explain the broadening of the size distribution observed in this study prior to coagulum formation as shown in Fig. 2b, c. The faster increase in hydrodynamic radius of lager micelles due to dissociation within casein micelles compared to smaller ones might explain a broader size distribution of casein micelles after a certain heat treatment.

In a second step, we additionally measured the particle size in this supernatant fraction by PCS for the detection of even smaller particles. We could observe that when aggregation of casein micelles occurs, a smaller fraction of particles in the range of 20-100 $\mathrm{nm}$ becomes a significant proportion of the distribution (Fig. 2c) whereby non-aggregated micelles become larger in size as also observed in laser light diffraction measurements (Fig. 2b). The particle size range of this small particle fraction was independent of temperature, holding time, and total solid content of CSM. However, the distribution of fractions only gave quantitative information about the relative distribution of these fractions within a certain sample. To isolate this fraction from the heat-treated CSM samples, to analyze its composition, and to study its quantitative evolution at different heating temperatures and holding times, we developed an ultracentrifugation protocol for complete removal of quasi-native casein micelles. At the same time, we wanted to ensure that these smaller submicellar particles remain quantitatively in the supernatant. We therefore determined the minimally required ultracentrifugation conditions for the removal of casein micelles from the samples. The required intensity of the centrifugal conditions for the removal of casein micelles was much lower compared to conditions used in literature (Singh and Fox 1987a, 1985; Singh and Creamer 1991; Carroll et al. 1971). This might be partly explained by considering that centrifugation conditions also depend on the size of the centrifuge tubes used which were comparably small $(1.4 \mathrm{~mL})$ in our study. The particle size distribution of these isolated particles is shown in Fig. 2d. A selection is shown for temperatures where these particles of 20-100 $\mathrm{nm}$ in size were present in a large quantity. Quality criteria for PCS measurements were not met for ultracentrifugal supernatants at lower temperatures, indicating a too small amount of particles present in the ultracentrifugal supernatants and thus a complete removal of casein micelles which would give a strong signal even at low concentration. Carroll et al. (1971) also observed small particles in concentrated milks by electron microscopy and suggested that it is not only composed of denatured whey protein particles, but rather composed of "small micellar units" as they called it.

A dilution step prior to ultracentrifugation was introduced to minimize interactions between particles during sedimentation. In addition, dilution of the samples was a necessary step to reduce the volume of the pellet and its significance on the 
results obtained. Concerns about the implications of the dilution with distilled water on casein micelle might be raised. However, total CSM solid content of minimum $18 \%$ was diluted by a dilution factor of 2.8 for ultracentrifugation at $48,800 \times \mathrm{g} / 26$ min which means that the minimum ionic strength was $67 \%$ of the original unconcentrated milk. The same procedure was used for all total solid contents which resulted in a relative ionic strength of 85.5 and $100 \%$ for 23 and $27 \%$ total solids, respectively. For ultracentrifugation at $70,000 \times \mathrm{g} / 60 \mathrm{~min}$, the dilution factor was about 3 as shown in Fig. 1. Ultracentrifugation was performed immediately after dilution within $1 \mathrm{~h}$. The insignificance of the dilution step was proven by our RP-HPLC results of unheated samples presented later in this study. These did not differ for different dilutions of the unheated samples.

Figure 2 was one example for the different fractions of particles in CSM at 23\% total solids after heat treatment. To further investigate the effects of total solids, temperature, and time of heat treatment on casein micelle size using DSI, the changes in particle size should be related to heat-induced dissociation of protein material from casein micelles and micelle aggregation. Figure 3 shows the volume-based average particle diameter $\mathrm{d}_{50,3}$ of casein micelle supernatants in heated CSM. It can be observed that in general, the mean diameter of casein micelles increases with increasing heating temperature and holding time at a constant total solid content (Fig. 3a) and increases with increasing total solid content at a constant temperature-time combination (Fig. $3 \mathrm{~b}$ ) for 18 and $27 \%$ total solids. Samples of CSM with $23 \%$ total solids and 10 s holding time were also presented as data for a holding time of $6 \mathrm{~s}$ were not investigated. From these results, we concluded that preheating to $95^{\circ} \mathrm{C}$ without direct steam injection did not largely affect casein micelle size in the range of total solid content investigated. At higher temperatures, there is a steady increase of casein micelle size and up to a more than twofold increase in size at a maximum. These observations should be born in mind as we will refer these observations to protein dissociation and heat-induced aggregation.
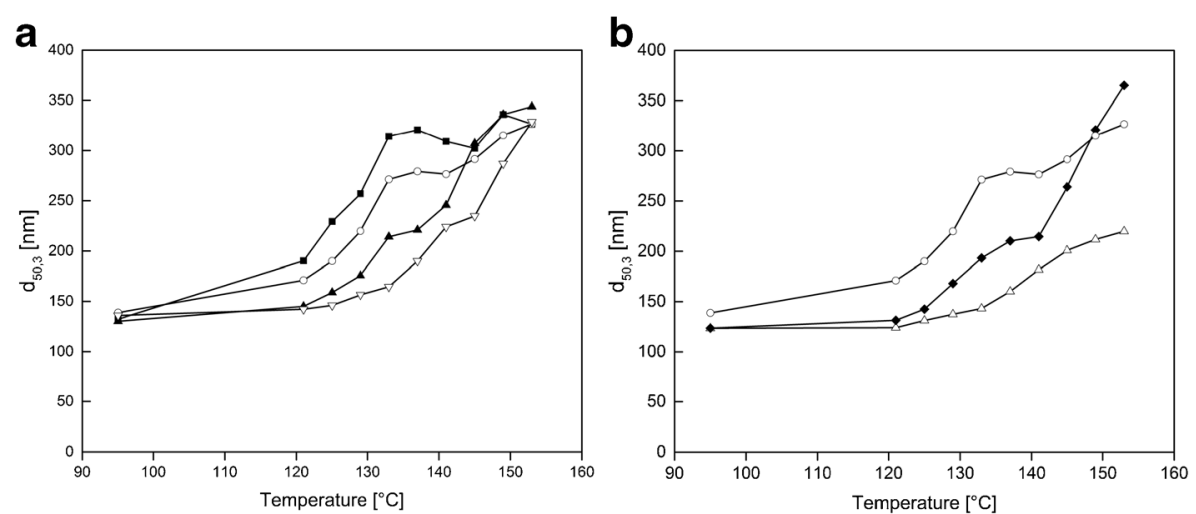

Fig. 3 Average volume-based particle diameter $\mathrm{d}_{50,3}$ as a function of temperature, total solids, and holding time of DSI heat treatments. a Shows holding times of $0.5 \mathrm{~s}$ (open triangles), $2 \mathrm{~s}$ (closed triangles), $6 \mathrm{~s}$ (open circles), and $13 \mathrm{~s}$ holding time (closed squares) at $27 \%$ total solids of the supernatant $(4000 \times \mathrm{g} / 10 \mathrm{~min})$ of CSM samples. b Shows the average volume-based particle size $\mathrm{d}_{50,3}$ as a function of total solids for $18 \% \mathrm{TS} /$ $6 \mathrm{~s}$ (open triangles), 23\% TS/10 s (closed diamonds), and 27\% TS/6 s (open circles) 


\subsection{Heat-induced aggregation of caseins in concentrated skim milk}

To follow the aggregation process in CSM at different heating temperatures which led to distinct and separable large particles, we used RP-HPLC to separate the individual caseins and whey proteins remaining in the supernatant fraction of $4,000 \times \mathrm{g} / 10 \mathrm{~min}$ in a first step. Figure 4 shows three different chromatograms of caseins and whey proteins as an example indicating the aggregation of $\alpha_{\mathrm{S}}$-caseins and $\beta$-casein and also some whey protein with increasing heating temperature. The dilution of the sample with guanidine buffer gave a better resolution of individual proteins compared to dissolution of milk samples in urea buffer as used by Rauh et al. (2014), Bonizzi et al. (2009), and Visser et al. (1991). In the case of whey proteins, higher heat intensity leads to a pre-peak formation due to non-enzymatic glycosylation of whey proteins with lactose as described by Rauh et al. (2015). By using this method, we could quantitatively follow the heatinduced aggregation process of individual caseins at heated different temperatures and heat holding times at constant non-fat total solid content of $27 \%$ as presented in Fig. 5. It was observed that calcium-sensitive $\alpha_{\mathrm{S}}$-caseins and $\beta$-casein start to become sedimentable due to aggregation when a critical temperature-time combination is exceeded. The amount of aggregated $\beta$-casein was significantly lower $(p<0.05)$ compared to $\alpha_{\mathrm{S}^{-}}$ casein for samples where aggregated protein was present. It is interesting to note at this point that samples were completely stable up to a certain critical temperature. Exceeding this critical temperature led to a rapid increase of coagulated sedimentable protein.

In contrast to this, $\mathrm{K}$-casein content decreased with increasing holding time to a much lesser extent and there was no marked difference between holding times. These observations are in agreement with the results of Mora-Gutierrez et al. (1993) concerning the calcium sensitivity and tendency of self-association of individual caseins when we consider heat-induced coagulation as a heat-induced re-arrangement

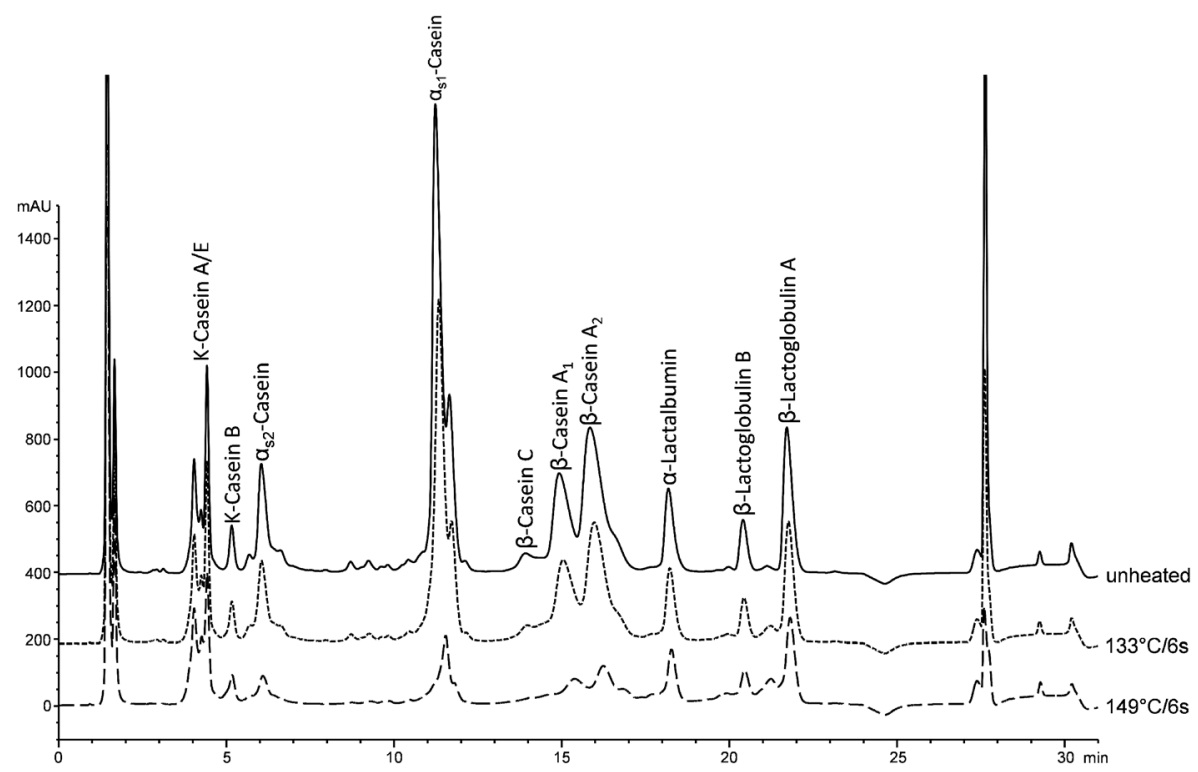

Fig. 4 RP-HPLC chromatograms of supernatants $(4000 \times \mathrm{g} / 10 \mathrm{~min})$ of caseins and whey proteins in guanidine buffer. Three samples are shown indicating the reduction of calcium-sensitive caseins in the supernatant 

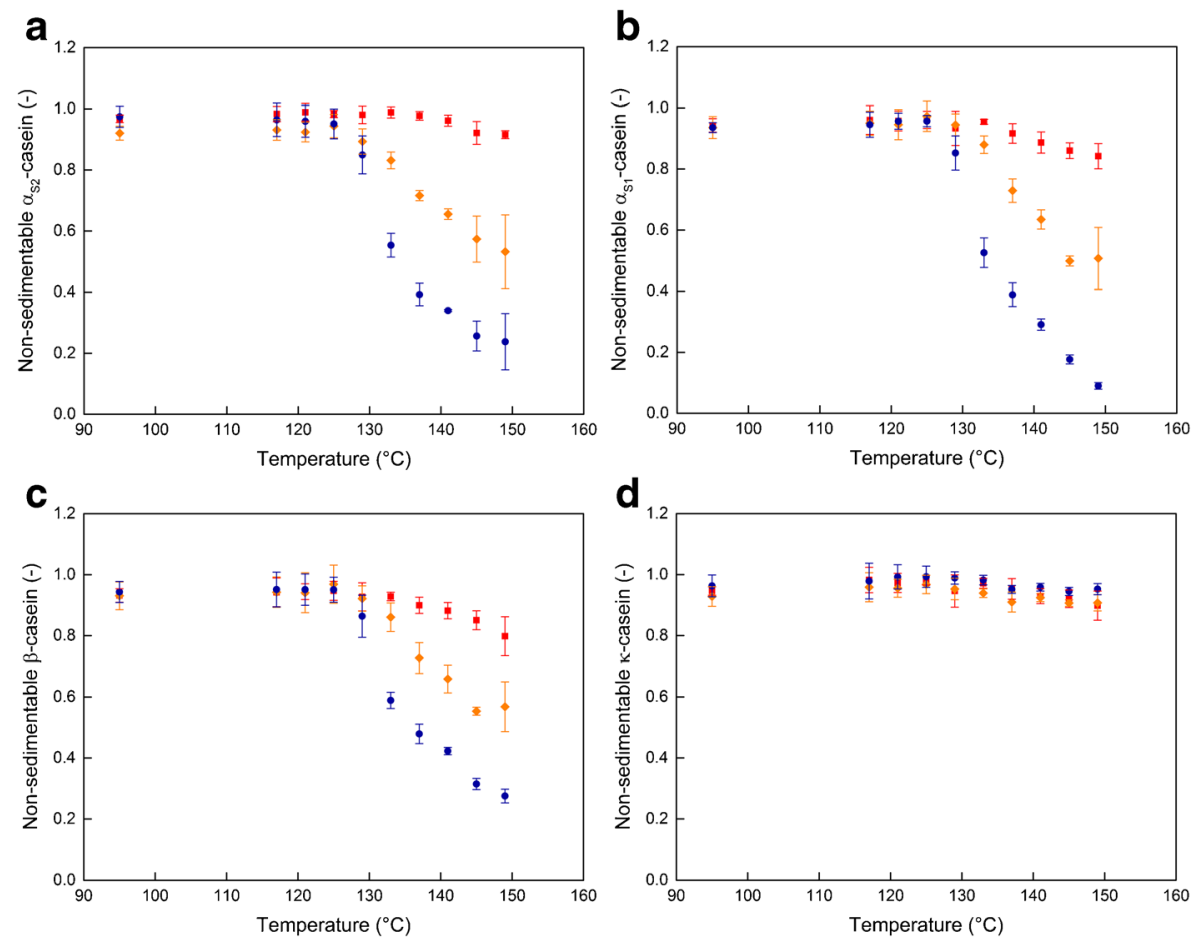

Fig. 5 Relative amount of non-sedimentable caseins in CSM at $27 \%$ total solids centrifuged at $4000 \times \mathrm{g}$ for $10 \mathrm{~min}$ heated at different temperatures and holding times of $0.5 \mathrm{~s}$ (squares), $2 \mathrm{~s}$ (diamonds), and $10 \mathrm{~s}$ (circles). a $\alpha_{\mathrm{S} 2}$-casein, $\mathbf{b} \alpha_{\mathrm{S} 1}$-casein, $\mathbf{c} \beta$-casein, $\mathbf{d}$ k-casein

process. Interestingly, the tendency of heat-induced aggregation of the individual caseins in the order

$$
\alpha_{\mathrm{S} 1} \geq \alpha_{\mathrm{S} 2}>\beta>>\kappa
$$

was contrary to the dissociation behavior of individual caseins from casein micelles in milk heated at high temperature observed by Anema and Klostermeyer (1997), Singh and Creamer (1991), and Holt et al. (1986). The as-caseins in milk are known to be the most calcium-sensitive caseins due to their phosphoserine-containing polypeptide chain (Holt et al. 2013). These observations may also be related to the position of the caseins within the casein micelle which fosters the dissociation of caseins from the outer surface rather than the core regions of the micelle. $K$ - and $\beta$-caseins are also known to be more loosely bound to the casein micelle by hydrophobic interactions (Holt et al. 2013; Dalgleish and Corredig 2012). Dissociated caseins were not incorporated into large aggregates. This could be a result of the self-association of $\kappa$ - and $\beta$-caseins into stable soluble complexes together with whey proteins in the size range of 20-100 nm (fraction 3). A slight decrease in the amount of non-sedimentable $\mathrm{K}$-casein might be perceivable in Fig. 5 due to incomplete dissociation and co-aggregation with calciumsensitive caseins but could also be a result of thermal degradation. There was an indication for thermal degradation of caseins in the HPLC chromatograms as peaks of individual caseins were changing their shape. 
These results indicated that heat-induced coagulation and the subsequent sedimentability of protein are mainly a result of the heat-induced aggregation of $\mathrm{K}$ casein-depleted calcium-sensitive micelles. The calcium-sensitive caseins in the core of casein micelles contribute to most of the protein present in CSM as determined as sedimentable protein at high temperatures in a previous publication (Dumpler and Kulozik 2016). Therefore, this aggregation process as second step must be a temperature-time-dependent reaction that is limited by a preceding rate-determining reaction of $\mathrm{k}$-casein dissociation. Considering the results of particle size measurements, we suggest that the dissociated material does not form soluble proteins but tends to form new quasi-micellar structures that we observed in supernatants of strongly coagulated samples as presented in Fig. 2c, d.

\subsection{Critical level of casein dissociation to induce coagulation}

Following this hypothesis, we investigated centrifugation conditions that quantitatively separated these small particles from quasi-native casein micelles. Soluble proteins like undenatured whey proteins and soluble caseins are also included in this fraction. Examples for the chromatograms of differently heat-treated CSM of $27 \%$ total solids centrifuged at $48,800 \times g$ for 26 min are shown in Fig. 6 . It can be seen from the chromatograms that mainly the amount of $\mathrm{K}$-casein increased significantly with increasing intensity of heat treatment whereby the amount of calcium-sensitive casein increased to a lesser extent. Figure 7 shows the amount of non-sedimentable caseins in the centrifugal supernatant obtained at $4,000 \times g$ for 10 min (closed symbols) and the ultracentrifugal supernatant from samples centrifuged at $48,800 \times \mathrm{g}$ for $26 \mathrm{~min}$ (open symbols). Three different CSMs with varying total solid content of 18,23 , and $27 \%$ total solids were investigated. Holding time was 6,10 , and $6 \mathrm{~s}$, respectively. The graphs show that the onset of coagulation, indicated by the rapid decrease of non-sedimentable calcium-sensitive caseins, as well as the extent of coagulation are both dependent on CSM total

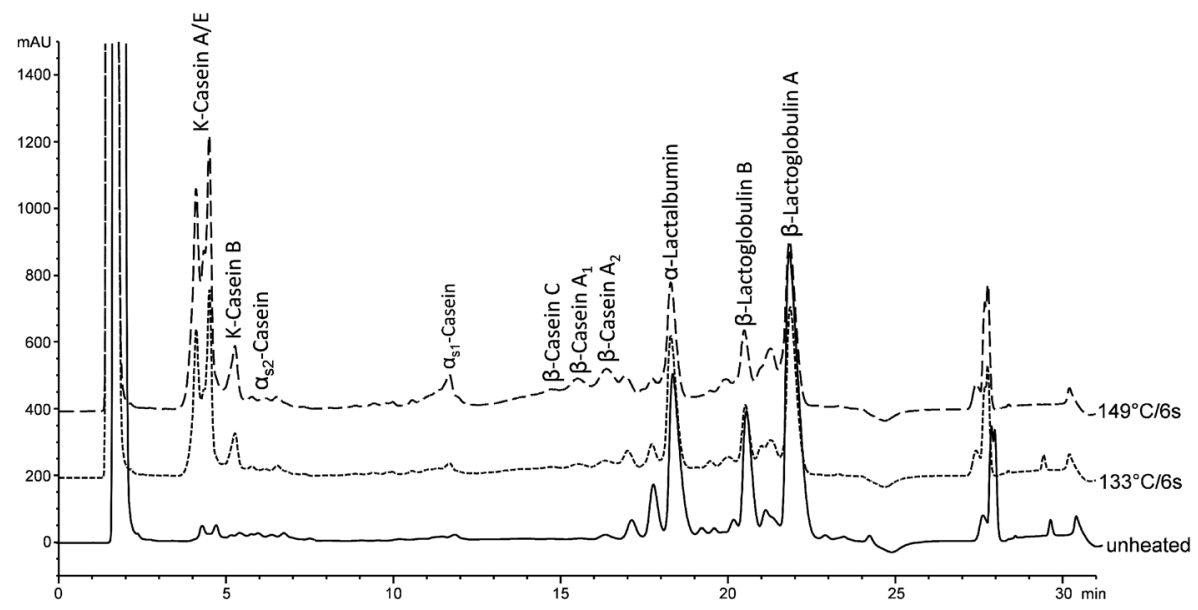

Fig. 6 RP-HPLC chromatograms of supernatants $(48,800 \times \mathrm{g} / 26 \mathrm{~min})$ of caseins and whey proteins in guanidine buffer. Three samples are shown indicating the increase in the amount of $\mathrm{K}$-casein in the supernatant with increasing heating temperature 
a

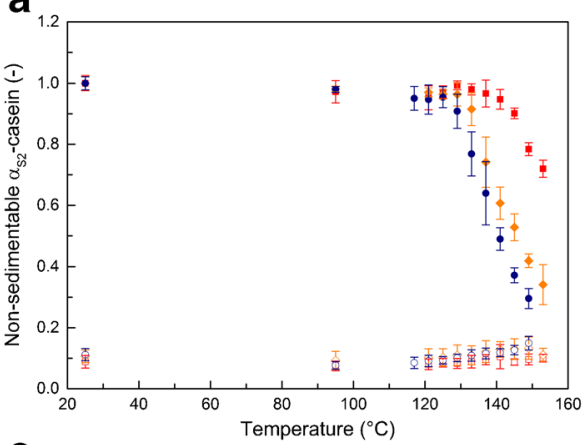

C

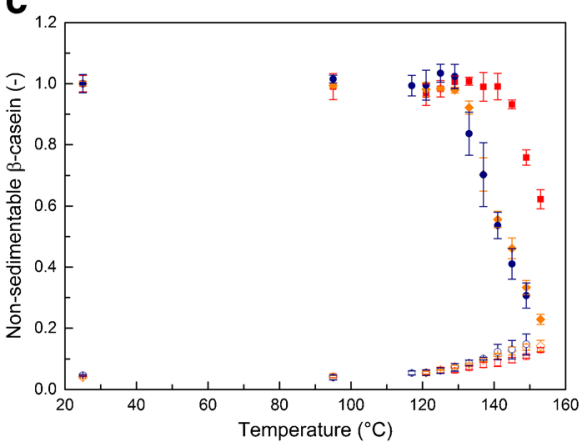

b

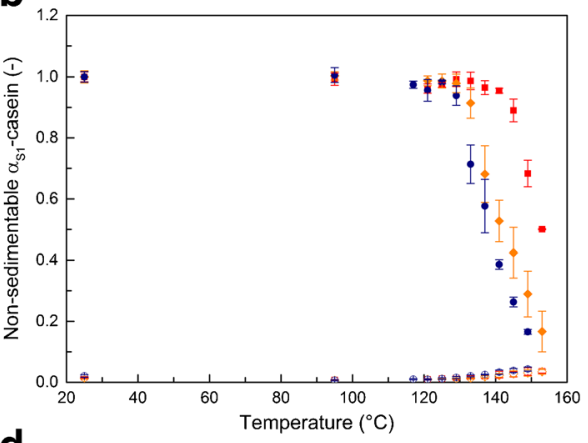

d

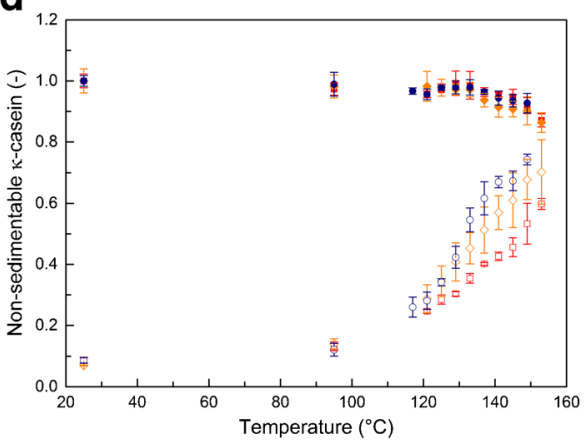

Fig. 7 Relative amount of non-sedimentable caseins in CSM at 18\%/6 s holding time (squares), 23\% totals solids $/ 10 \mathrm{~s}$ (diamonds), and $27 \%$ total solids $/ 6 \mathrm{~s}$ centrifuged at $4000 \times \mathrm{g}$ for $10 \mathrm{~min}$ (closed symbols) and $48,800 \times g / 26 \min \left(\right.$ open symbols) heated at different temperatures. a $\alpha_{\mathrm{S} 2}$-casein, $\mathbf{b} \alpha_{\mathrm{S} 1}$-casein, $\mathbf{c} \beta$-casein, $\mathbf{d ~ k -}$ casein

solids as well as holding time at a certain temperature. The reduction of the relative amount of $\mathrm{K}$-casein was seen to be also unaffected of CSM total solids and did not coagulate to a large extent together with calcium-sensitive caseins. The coagulation of $\beta$-casein was again less compared to $\alpha_{\mathrm{S} 1 \text {-casein. It is therefore }}$ most likely that $\mathrm{K}$-casein-depleted calcium-sensitive micelles aggregate as spherical protein particles to form large sedimentable particles.

The dissociation of individual caseins was inversely related to the tendency of caseins toward aggregation. There was a very limited dissociation of calciumsensitive $\alpha_{\mathrm{S}}$-caseins. The apparent presence of a certain amount of $\alpha_{\mathrm{S} 2}$-casein in the serum phase is likely to be the result of peptides underlying the peak of $\alpha_{\mathrm{S} 2 \text {-casein. }}$ Considering this, the extent of heat-induced $\beta$-casein dissociation (Fig. 7c) was significantly higher $(p<0.01)$ compared to $\alpha_{S^{-}}$caseins at constant total solid content. The extent of $\mathrm{k}$-casein dissociation was found to increase linearly with temperature and total solid content of CSM to a large extent as shown in Fig. 7d (open symbols). At the highest temperature applied, between 60 and up to $80 \%$ of $\mathrm{K}$-casein had dissociated from the micelles into fraction 3 (small submicellar particles) at 18 and 27\% total solids, respectively. At the same time, between 50 and up to $80 \%$ of calcium-sensitive casein had aggregated to large sedimentable particles (fraction 1). The effect of total solids on the integration of calcium-sensitive caseins into fraction 3 was not significantly different $(p<0.05)$. 
The results indicate that $\mathrm{K}$-casein dissociation limits the aggregation of calciumsensitive caseins during the coagulation process. In addition, we assumed that individual micelles having higher $\mathrm{K}$-casein content relative to the amount of calcium-sensitive caseins, i.e., especially smaller casein micelles, are less prone to dissociation and aggregation. This was also proposed and investigated by O'Connell and Fox (2000) and Aoki and Kako (1983). To address this hypothesis, the relative distribution of caseins in fraction 2 (quasi-native micelles) was calculated from the difference in the amounts present in fraction 1 (large particles) and dissociated and soluble proteins (fraction 3 and 4) using the data presented in Fig. 7. As a result, we found that the relative amount of $\mathrm{K}$-casein based on the total amount of caseins in the fraction of nonaggregated quasi-native micelles (fraction 2) was decreasing due to dissociation of Kcasein up to the critical temperature of coagulation at 18,23 , and $27 \%$ of total solids. With further increasing temperature, at the point where a large proportion of calciumsensitive caseins starts to aggregate, the proportion of $\mathrm{K}$-casein within fraction 2 is increasing again, indicating that smaller, K-casein-rich micelles are more resistant toward heat-induced coagulation. Most interestingly, the critical relative amount of $\mathrm{K}$ casein dissociation at the onset of coagulation in CSM heat-treated by direct steam injection was in the range of 30 to $35 \%$ taking into account $8 \%$ of dissociated $\mathrm{K}$-casein in the unheated CSM.

The observations that $\mathrm{K}$-casein does not aggregate together with calcium-sensitive caseins, that there is a critical level of $\mathrm{k}$-casein dissociation that is likely to induce coagulation, and that the $\mathrm{K}$-casein to calcium-sensitive casein ratio within the population of non-aggregated micelles increases led us to the following conclusion. There is a distribution within the population of micelles in terms of $\mathrm{K}$-casein depletion that tends toward aggregation. Completely depleted micelles become present at a certain temperature and holding time, and this population grows faster under more unfavorable conditions, i.e., higher total solid content and tends toward coagulation.

\subsection{Effect of temperature and heating time on aggregation and dissociation of $\alpha$-lactalbumin and $\beta$-lactoglobulin}

Whey proteins are known to interact with $\mathrm{K}$-casein either during heat treatment of milk or concentrated milk. Structures that form during heat treatment can be very variable due to the changing reactivity of the free thiol group of $\beta$-lactoglobulin $(\beta-\mathrm{Lg})$ at different $\mathrm{pH}$ values. This interaction was found to lead to soluble $\beta$-lactoglobulin- $\mathrm{K}-$ casein complexes when heat-induced dissociation of $\beta$-lactoglobulin- $K$-casein-complexes from casein micelles occurs. In another proposal for the formation of these complexes, it was suggested that dissociated $\mathrm{K}$-casein forms disulfide linkages in the serum phase and the subsequent re-association of $\mathrm{K}$-casein is hampered and thereby reduces the stability of the casein micelles. $\alpha$-Lactalbumin ( $\alpha$-La) is known to form complexes with $\beta$-Lg during heat treatment, and it was shown that $\alpha$-La- $\beta$-Lg-K-casein complexes are possible in the presence of $\beta$-Lg in milk (Donato and Guyomarc'h 2009; Anema and Li 2003). Hence, the observed dissociation of $\mathrm{K}$-casein and subsequent aggregation of the calcium sensitive caseins should lead to a redistribution of whey proteins as well. Figure 8 shows the distribution of the whey proteins $\alpha$-La and $\beta-\mathrm{Lg}$ in the fractions ultracentrifugal supernatant (open symbols) and the large sedimentable aggregates (closed 

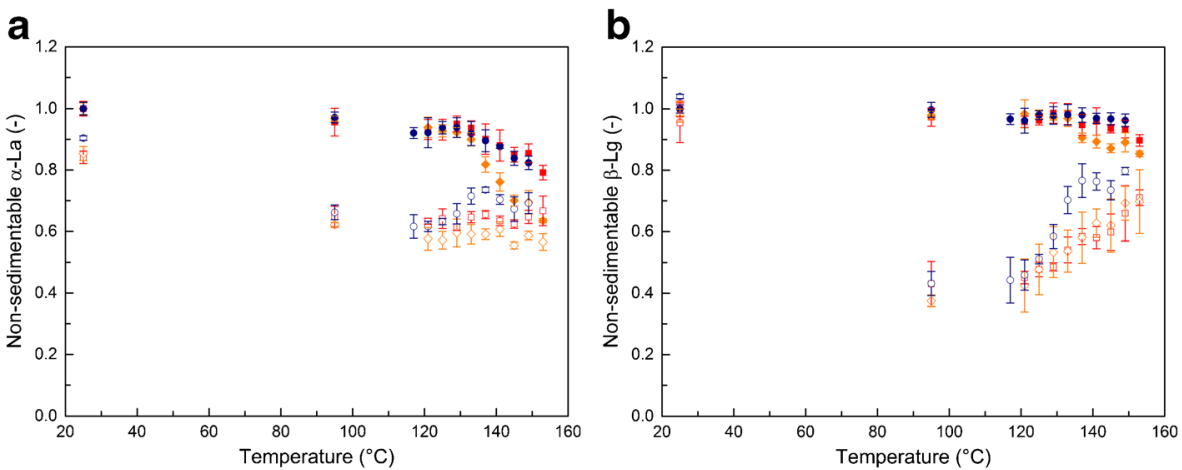

Fig. 8 Relative amount of non-sedimentable whey proteins in CSM at 18\%/6 s holding time (squares), 23\% totals solids $/ 10 \mathrm{~s}$ (diamonds), and $27 \%$ total solids $/ 6 \mathrm{~s}$ centrifuged at $4000 \times \mathrm{g}$ for $10 \mathrm{~min}$ (closed symbols), and $48,800 \times g / 26 \mathrm{~min}$ (open symbols) heated at different temperatures. a $\alpha$-lactalbumin, b $\beta$-lactoglobulin

symbols). The fraction of casein micelles and particles in this size range is again represented by the residual amount. About $10 \%$ of $\alpha$-La was not soluble in CSM (Fig. 8a). This may be due to pasteurization of the milk prior to concentration. Additional $20 \%$ of $\alpha$-La got associated with the casein micelles during pre-heating to $95{ }^{\circ} \mathrm{C}$ without steam injection. The degree of denaturation of $\alpha$-La was about $30-35 \%$ after pre-heating so that more than half of the denatured $\alpha$-La got associated with casein micelles and therefore sedimentable. The degree of denaturation was determined as described by Dumpler and Kulozik (2016). However, no differentiation between undenatured $\alpha$-La and small colloidal complexes with $\beta$-Lg could be made. At higher temperatures, $\alpha$-La dissociates again from the micelles to some extent, the dissociation being more pronounced at higher total solid content of CSM. Above $140{ }^{\circ} \mathrm{C}$, there might be an aggregation into larger particles and also some thermal degradation of $\alpha$-La as the relative amount of $\alpha$-La decreases in both fractions 1 and 3 .

Figure $8 \mathrm{~b}$ shows that $\beta-\mathrm{Lg}$ association with the casein micelles is more strongly pronounced compared to $\alpha$-La when CSM is pre-heated to $95{ }^{\circ} \mathrm{C}$. About $60 \%$ of $\beta$ - $\mathrm{Lg}$ associates with casein micelles and becomes sedimentable by ultracentrifugation. Increasing the heating temperature resulted in a dissociation of $\beta-\mathrm{Lg}$ from casein micelles that resembles the behavior of $\mathrm{K}$-casein, and therefore, we assume that $\beta$-Lg-K-casein complexes dissociate from the micelles including some associated $\alpha$-La. Again, the dissociation of $\beta$-Lg was more pronounced when the total solid content of CSM was higher at a constant temperature. Sedimentation of $\beta-\mathrm{Lg}$ together with calcium-sensitive caseins was very limited. Whey proteins may therefore exist in four different forms distributed in each fraction in CSM when heat-induced aggregation occurs. These different forms can be denoted in descending order of their corresponding amount: dissociated whey protein-K-casein complexes, soluble denatured whey protein complexes, native whey proteins, and co-sedimenting whey protein-casein aggregates.

\subsection{Amount of soluble protein formed during heat treatment of concentrated skim milk}

Figure 9 shows the amount of soluble $\beta$-casein and $k$-casein in the ultracentrifugal supernatant obtained after centrifugation at $70,000 \times g$ for $60 \mathrm{~min}$ depending on holding 

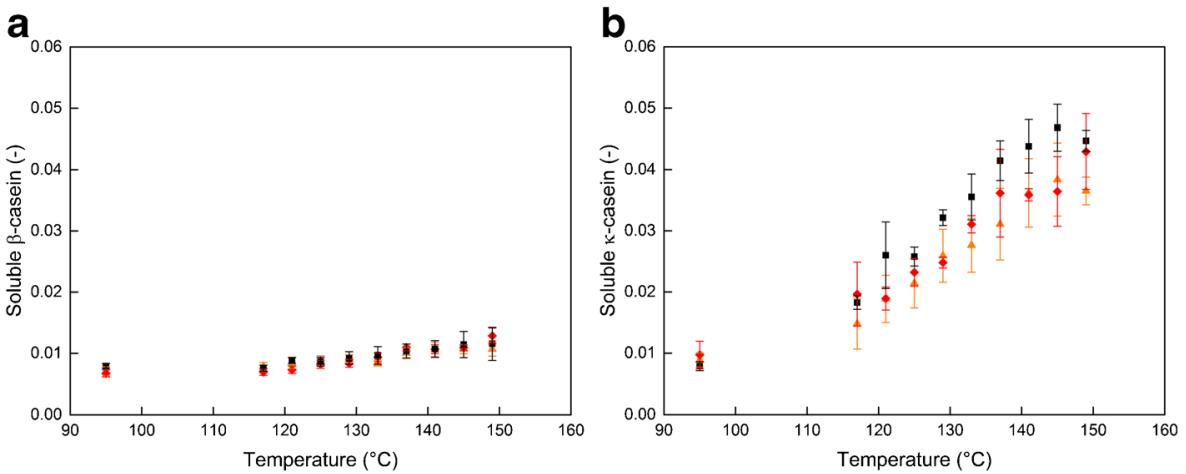

Fig. 9 Relative amount of a soluble $\beta$-casein and $\mathbf{b}$ soluble $\mathrm{K}$-casein in the ultracentrifugal supernatant $(70,000 \times \mathrm{g} / 60 \mathrm{~min})$ after heat treatment of concentrated skim milk of $27 \%$ total solids at different temperatures for $2 \mathrm{~s}$ (triangles), $6 \mathrm{~s}$ (diamonds), and $13 \mathrm{~s}$ (squares)

time and temperature of CSM with $27 \%$ total solids. $\alpha_{\mathrm{S}}$-Caseins could not be detected in the ultracentrifugal supernatant at 70,000 $\mathrm{g}$ for $60 \mathrm{~min}$. By comparison of Fig. 9a, b, it turns out that the amount of soluble $\mathrm{K}$-casein is independent of the aggregation of calcium-sensitive caseins and rather follows the dissociation of $\kappa$-casein- $\beta-\mathrm{Lg}$ complexes from the micelle surface as shown in Fig. $7 \mathrm{~d}$. The amount of $\mathrm{k}$-casein rather increases linearly with temperature and was found to be not significantly higher

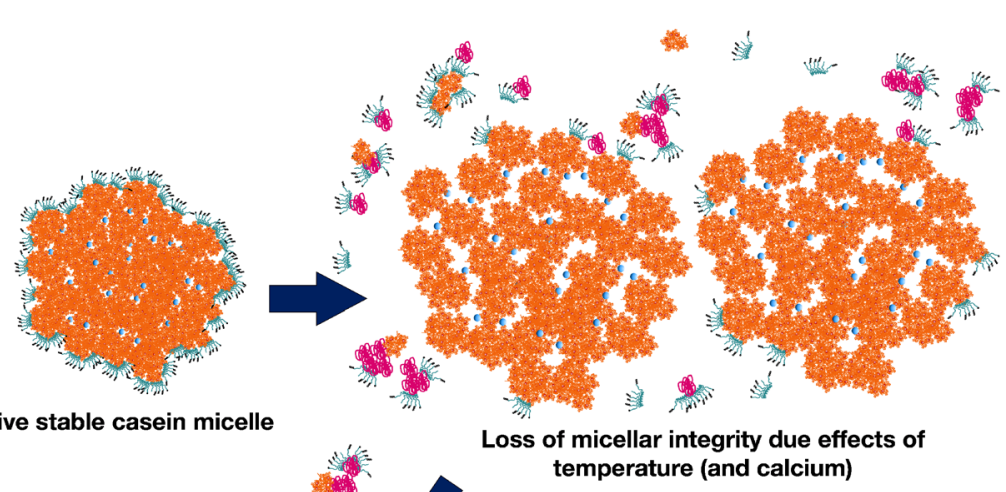

\section{Aggregation and sedimentation of} calcium sensitive caseins

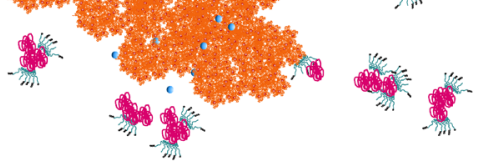

denat. Whey protein

- ionic calcium

$\mathrm{a}_{\mathrm{s} 1}, \mathrm{a}_{\mathrm{s} 2}, \beta$-casein

- Calcium phosphate nanocluster

$\checkmark$ Sugar residue

Fig. 10 Schematic representation of the proposed model of heat-induced dissociation and coagulation of caseins and whey proteins in CSM derived from the distribution analysis of individual proteins 
$(p>0.1)$ when the holding time was longer. However, at least means were higher at longer holding times. The amount of soluble K-casein (Fig. 9b) divided by the amount of $\mathrm{K}$-casein dissociated from casein micelles (Fig. $7 \mathrm{~d}$ ) is in the range of 6 to $8 \%$ at all temperatures. The overall amount of soluble $\beta$-casein was found to be not significantly different between heat treatments in terms of holding time and total solids $(p>0.1)$ and was at all temperatures less than $1.5 \%$ of total $\beta$-casein. Soluble protein was therefore found to be a minor fraction that cannot explain the onset and propagation of coagulation of casein micelles. When we consider the small particles and the amount of dissociated $\mathrm{K}$-casein found within this fraction, we can conclude that for a sedimentation of $70 \%$ of caseins in sum $\left(27 \% \mathrm{TS} ; 149{ }^{\circ} \mathrm{C} / 6 \mathrm{~s}\right), 80 \%$ of $\mathrm{K}$-caseins need to be dissociated from the micelle (Fig. $7 \mathrm{~d}, 149{ }^{\circ} \mathrm{C} / 6 \mathrm{~s}$ ). Thereby, we could close the mass balance of protein detected in different fractions. We concluded that the material dissociated from the micelles due to heat treatment of CSM is mainly incorporated in small colloidal quasi-micellar particles of 20-100 nm in diameter (fraction 3) as observed by PCS particle size measurements. These particles mainly consist of $\mathrm{K}-$ casein-whey protein complexes including comparably small amounts of calciumsensitive caseins. Proteins dissociated from the micelles were not found to be present as soluble protein after a certain amount of heat load to a large extent.

\section{Conclusions}

To conclude on the effects of heat treatment by direct steam injection on concentrated skim milk leading to heat-induced coagulation with special focus on casein micelles and whey proteins, we drew a schematic representation of the steps involved that could be derived from the analytical results. This model is shown in Fig. 10. It describes the conversion of a native, colloidally stable micelle into a dissociated form as a first step. Due to the activation energy supplied by heat, the micelle will dissociate into $\mathrm{K}$-caseinwhey protein complexes and calcium-sensitive $\mathrm{K}$-casein-depleted casein micelles. These micelles are increasingly loose in structure, much larger, and stronger hydrated compared to the native structure possibly due to the cleavage of the linkage between caseins and colloidal calcium phosphate as described by Aoki et al. (1990). This massive increase in hydrodynamic radius may induce or at least facilitate $\mathrm{K}$-casein dissociation and may increase attractive forces between micelles due to a much larger calcium-sensitive "sticky" contact area depleted in K-casein and therefore increase the rate of aggregation into large protein particles that are sedimentable. The observed effects of the increase in casein micelle size and the dissociation of $\mathrm{K}$-casein-whey protein complexes from the casein micelle surface were found to parallel each other as these effects both increased with increasing total solid content as well as heating temperature and time. Therefore, a close relationship between loosening of the internal micellar structure and protein dissociation leading to destabilization of casein micelles is likely. The effects of serum composition, $\mathrm{pH}$, and volume fraction of casein micelles on the velocity of $\mathrm{K}$-casein dissociation and especially the increase in hydrodynamic radius of casein micelles need to be further addressed. Crowley et al. (2015) have shown that an increase in ionic calcium increased the rate of $\mathrm{K}$-casein dissociation.

Most relevant in this work was the observation that heat-dissociated proteins were not found as soluble in the serum phase but rather form submicellar colloidal particles 
together with denatured whey protein that can be separated by ultracentrifugation. Ultracentrifugation conditions that removed all colloidal particles from milk used in literature might have underestimated the extent of dissociation of casein from the micelles during heat treatment.

In addition, we could gain new insights into the second undesired step of heatinduced coagulation which is the aggregation process leading to a redistribution of caseins into different size fractions and the formation of new structures. When a direct high heat process is applied for preservation of liquid CSM for the reduction of the environmental impact of the dairy industry by using CSM as a skim milk powder substitute, results obtained in this study will be most relevant.

Acknowledgments We would like to appreciate the work of Alexander Hainz that he did on this project during his Bachelor's thesis in sample preparation and analysis. Günther Unterbuchberger and Christian Gottwald are acknowledged for operation and maintenance of the reverse osmosis and UHT pilot plants. The project was supported by funds of the Federal Ministry of Food and Agriculture (BMEL) based on a decision of the Parliament of the Federal Republic of Germany via the Federal Office for Agriculture and Food (BLE) under the innovation support program (grant number 313.06.01-28-1-74.005-11).

Compliance with ethical standards This article does not contain any studies with human or animal subjects performed by any of the authors.

Conflict of interest The authors declare that they have no conflict of interest.

\section{References}

Anema SG (1998) Effect of milk concentration on heat-induced, pH-dependent dissociation of casein from micelles in reconstituted skim milk at temperatures between 20 and $120^{\circ} \mathrm{C}$. J Agric Food Chem 46:22992305

Anema SG, Klostermeyer H (1997) Heat-induced, pH-dependent dissociation of casein micelles on heating reconstituted skim milk at temperatures below $100^{\circ} \mathrm{C}$. J Agric Food Chem 45:1108-1115

Anema SG, Li Y (2003) Effect of pH on the association of denatured whey proteins with casein micelles in heated reconstituted skim milk. J Agric Food Chem 51:1640-1646

Aoki T, Kako Y (1983) Relation between micelle size and formation of soluble casein on heating concentrated milk. J Dairy Res 50

Aoki T, Umeda T, Kako Y (1990) Cleavage of the linkage between colloidal calcium phosphate and casein on heating milk at high temperature. J Dairy Res 57:349-354

Bobe G, Beitz DC, Freeman AE, Lindberg GL (1998) Separation and quantification of bovine milk proteins by reversed-phase high-performance liquid chromatography. J Agric Food Chem 46:458-463

Bonfatti V, Grigoletto L, Cecchinato A, Gallo L, Carnier P (2008) Validation of a new reversed-phase highperformance liquid chromatography method for separation and quantification of bovine milk protein genetic variants. J Chromatogr A 1195:101-106

Bonizzi I, Buffoni JN, Feligini M (2009) Quantification of bovine casein fractions by direct chromatographic analysis of milk. Approaching the application to a real production context. J Chromatogr A 1216:165-168

Carroll RJ, Thompson MP, Melnychyn P (1971) Gelation of concentrated skimmilk: electron microscopic study. J Dairy Sci 54:1245-1252

Crowley SV, Megemont M, Gazi I, Kelly AL, Huppertz T, O’Mahony JA (2014) Heat stability of reconstituted milk protein concentrate powders. Int Dairy J 37:104-110

Crowley SV, Boudin M, Chen BY, Gazi I, Huppertz T, Kelly AL, O’Mahony JA (2015) Stability of milk protein concentrate suspensions to in-container sterilisation heating conditions. Int Dairy J 50:45-49

Dalgleish DG, Corredig M (2012) The structure of the casein micelle of milk and its changes during processing. Ann Rev Food Sci Technol 3:449-467 
Donato L, Guyomarc'h F (2009) Formation and properties of the whey protein/K-casein complexes in heated skim milk—a review. Dairy Sci \& Technol 89:3-29

Dumpler J, Kulozik U (2015) Heat stability of concentrated skim milk as a function of heating time and temperature on a laboratory scale_-improved methodology and kinetic relationship. Int Dairy J 49:111117

Dumpler J, Kulozik U (2016) Heat-induced coagulation of concentrated skim milk heated by direct steam injection. Int Dairy J 59:62-71

Fox PF (1981) Heat-induced changes in milk preceding coagulation. J Dairy Sci 64:2127-2137

Fox PF, Hearn CM (1978) Heat stability of milk: influence of denaturable proteins and detergents on $\mathrm{pH}$ sensitivity. J Dairy Res 45:159-172

Greene RF Jr, Pace CN (1974) Urea and guanidine hydrochloride denaturation of ribonuclease, lysozyme, $\alpha$ chymotrypsin, and $\beta$-lactoglobulin. J Biol Chem 249:5388-5393

Hinrichs J (2000) UHT processed milk concentrates. Lait 80:15-23

Holt C, Davies DT, Law AJR (1986) Effects of colloidal calcium phosphate content and free calcium ion concentration in the milk serum on the dissociation of bovine casein micelles. J Dairy Res 53:557-572

Holt C, Carver JA, Ecroyd H, Thorn DC (2013) Invited review: caseins and the casein micelle: their biological functions, structures, and behavior in foods. J Dairy Sci 96:6127-6146

Huppertz T (2014) Heat stability of transglutaminase-treated milk. Int Dairy J 38:183-186

Huppertz T, Fox PF (2006) Effect of $\mathrm{NaCl}$ on some physico-chemical properties of concentrated bovine milk. Int Dairy J 16:1142-1148

Jenness R, Koops J (1962) Preparation and properites of a salt solution which simulates milk ultrafiltrate. Neth Milk Dairy J 16:153-164

Kelly PM, Roefs SPFM (1990) Comparison of a klarograph and oil-bath methods for the measurement of the heat stability of reconstituted milks. Irish. J Food Sci Technol 14:132

Mora-Gutierrez A, Farrell HM Jr, Kumosinski TF (1993) Comparison of calcium-induced associations of bovine and caprine caseins and the relationship of $\alpha_{\mathrm{s} 1}$-casein content to colloidal stabilization: a thermodynamic linkage analysis ${ }^{1}$ : journal of dairy science. J Dairy Sci 76:3690-3697

Morrissey PA (1969) The heat stability of milk as affected by variations in pH and milk salts. J Dairy Res 36 : 343-351

Muir DD (1984) UHT-sterilized milk concentrate: a review of practical methods of production. Int J Dairy Tech 37:135-141

Muir DD, Sweetsur AWM, Holt C (1979) The synergic effect of urea and aldehydes on the heat stability of concentrated skim-milk. J Dairy Res 46:381-384

O'Connell JE, Fox PF (2000) The two-stage coagulation of milk proteins in the minimum of the heat coagulation time-pH profile of milk: effect of casein micelle size. J Dairy Sci 83:378-386

Olivares ML, Achkar NP, Zorrilla SE (2016) Rheological behavior of concentrated skim milk dispersions as affected by physicochemical conditions: change in $\mathrm{pH}$ and $\mathrm{CaCl} 2$ addition. Dairy Sci \& Technol:1-14

On-Nom N, Grandison AS, Lewis MJ (2012) Heat stability of milk supplemented with calcium chloride. J Dairy Sci 95:1623-1631

Rauh VM, Sundgren A, Bakman M, Ipsen R, Paulsson M, Larsen LB, Hammershøj M (2014) Plasmin activity as a possible cause for age gelation in UHT milk produced by direct steam infusion. Int Dairy J 38:199207

Rauh VM, Johansen LB, Bakman M, Ipsen R, Paulsson M, Larsen LB, Hammershøj M (2015) Protein lactosylation in UHT milk during storage measured by liquid chromatography-mass spectrometry and quantification of furosine. Int J Dairy Technol 68:486-494

Rose D (1961) Factors affecting the pH-sensitivity of the heat stability of milk from individual cows. J Dairy Sci 44:1405-1413

Rose D (1962) Factors affecting the heat stability of milk. J Dairy Sci 45:1305-1311

Sievanen K, Huppertz T, Kelly AL, Fox PF (2008) Influence of added calcium chloride on the heat stability of unconcentrated and concentrated bovine milk. Int J Dairy Tech 61:151-155

Singh H, Creamer LK (1991) Influence of concentration of milk solids on the dissociation of micellar K-casein on heating reconstituted milk at $120{ }^{\circ} \mathrm{C}$. J Dairy Res 58:99-105

Singh H, Fox PF (1985) Heat stability of milk: pH-dependent dissociation of micellar K-casein on heating milk at ultra high temperatures. J Dairy Res 52:529-538

Singh H, Fox PF (1986) Heat stability of milk: further studies on the pH-dependent dissociation of micellar Kcasein. J Dairy Res 53:237-248

Singh H, Fox PF (1987a) Heat stability of milk: influence of colloidal and soluble salts and protein modification on the $\mathrm{pH}$-dependent dissociation of micellar K-casein. J Dairy Res 54:523-534 
Singh H, Fox PF (1987b) Heat stability of milk: role of $\beta$-lactoglobulin in the $\mathrm{pH}$-dependent dissociation of micellar K-casein. J Dairy Res 54:509-521

Singh H, Latham JM (1993) Heat stability of milk: aggregation and dissociation of protein at ultra-high temperatures. Int Dairy J 3:225-237

Smith JF, Malmgren B (1999) UHT RCM - UHT recombined concentrated milk. In: International Dairy Federation (ed) 3rd International Symposium on Recombined Milk \& Milk Products: Special issue 9902. International Dairy Federation, Brussels, Belgium, pp 43-48

van Boekel MAJS, Nieuwenhuijse JA, Walstra P (1989) The heat coagulation of milk. 1. Mechanisms. Neth Milk Dairy J 43:97-127

Visser S, Slangen CJ, Rollema HS (1991) Phenotyping of bovine milk proteins by reversed-phase highperformance liquid chromatography. J Chromatogr A 548:361-370

White JCD, Davies DT (1958) 715. The relation between the chemical composition of milk and the stability of the caseinate complex: IV. Coagulation by heat. J Dairy Res 25:281

White JCD, Davies DT (1966) The stability of milk protein to heat: III. Objective measurement of heat stability of milk. J Dairy Res 33:93-102 